\title{
USO DE RECURSOS FAUNÍSTICOS EM COMUNIDADES À MONTANTE DA USINA HIDROELÉTRICA DE CURUÁ-UNA, MOJUÍ DOS CAMPOS, PARÁ
}

Use of fauna resources in five communities upstream of the Curuá-Una Hydroelectric Plant, Mojuí dos Campos, Pará

Uso de recursos faunísticos en comunidades anteriores a la central Hidroeléctrica de Curuá-Una, Mojuí de los Campos, Pará

\author{
Juliana Carlena Silva Lins Corrêa*1, Jhonatan Silva², Tony Marcos Porto Braga ${ }^{3 *}$ \\ ${ }^{1}$ Engenheira de Pesca pela Universidade Federal do Oeste do Pará - UFOPA. Santarém, Pará, Brasil. \\ ${ }^{2}$ Discente do Curso de Engenharia de Pesca na Universidade Federal do Oeste do Pará - UFOPA. Santarém, \\ Pará, Brasil. \\ ${ }^{3}$ Professor do Instituto de Ciências e Tecnologia das Águas (ICTA) da Universidade Federal do Oeste do Pará \\ (UFOPA), Santarém, Pará, Brasil.
}

*Correspondência: Instituto de Ciências e Tecnologia das Águas,Universidade Federal do Oeste do Pará, Rua Vera Paz, s/n Santarém, Pará, Brasil. CEP 68040-255E-mail: julyana-karlena@ hotmail.com.

\section{Artigo recebido em 03/04/2020 aprovado em 28/06/2021 publicado em 21/10/2021.}

\section{RESUMO}

Este trabalho teve como principal objetivo descrever as formas de uso dos recursos faunísticos pelos moradores de cinco comunidades situadas à montante da Usina Hidroelétrica de Curuá-Una, município de Mojuí dos campos, Pará. Os dados foram obtidos através de entrevistas, seguindo o método de "snowball" e analisados com estatística descritiva. Foram realizadas 71 entrevistas em cinco comunidades que fazem uso de recursos naturais para obtenção de renda ou alimentação. A agricultura aparece como principal atividade exercida para obtenção de renda e alimento. Registrou-se 35 espécies de animais destinados ao consumo, dentre estes, 25 são espécies de peixes, destacando-se o tucunaré (Cichla spp.), o charutinho (Hemiodus spp.) e as piranhas (Serrasalmus spp.; Pristobrycon spp.), representando $21,7 \%, 21,7 \%$ e $12 \%$, respectivamente. Além do peixe, os comunitários consomem outros animais, como galinha caipira (Gallus gallus), pato (Anatidae) e porco (Sus domesticus). Embora "proibido" o tracajá (Podocnemis unifilis) foi citado como o animal que esporadicamente é usado como alimento. Apesar da agricultura ser apontada como principal atividade econômica e de subsistência realizada nas comunidades, a pesca é de fundamental importância na vida dos comunitários, uma vez que é praticada durante o ano todo para obtenção de alimento e em alguns casos para a comercialização.

Palavras-chave: Comunidade ribeirinha, represas, Amazônia

\begin{abstract}
This work had as main objective to describe the forms of use of fauna resources by the residents of five communities located upstream of the Curuá-Una Hydroelectric Plant, municipality of Mojuí dos Campos, Pará. The data were obtained through interviews, following the method of Snowball, and analyzed with descriptive statistics. 71 interviews were carried out in the five communities that use natural resources to obtain income or food. Agriculture appears as the main activity exercised to obtain income and food. There were 35 species of animals destined for consumption, among these, 25 are species of fish, such as tucunaré (Cichla spp.), charutinho (Hemiodus spp) and piranhas (Serrasalmus spp.; Pristobrycon spp.), representing 21.7\%, $21.7 \%$ and $12 \%$, respectively. Besides the fish, the
\end{abstract}


community consume other animals, such as free-range chicken (Gallus gallus), duck (Anatidae) and pig (Sus domesticus). Although "forbidden" the tracajá (Podocnemis unifilis) was mentioned as the animal that is sporadically used as food. Although agriculture is identified as the main economic and subsistence activity carried out in communities, fishing is of fundamental importance in the life of community members, since it is practiced throughout the year to obtain food and in some cases for commercialization.

Key-words: Riparian community,dams, Amazon.

\section{RESUMEN}

Este trabajo tuvo como objetivo principal describir las formas de uso de los recursos de fauna por parte de los residentes de cinco comunidades ubicadas aguas arriba de la Central Hidroeléctrica Curuá-Una, municipio de Mojui dos campos, Pará. Los datos se obtuvieron mediante entrevistas, siguiendo el método de "Bola de nieve", y analizada con estadística descriptiva. Se realizaron 71 entrevistas en las cinco comunidades que utilizan los recursos naturales para obtener ingresos o alimentos. La agricultura aparece como la principal actividad ejercida para obtener ingresos y alimentos. Había 35 especies de animales destinados al consumo, entre ellas, 25 son especies de peces, destacando tucunaré (Cichla spp.), charutinho (Hemiodus spp.) Y las pirañas (Serrasalmus spp.; Pristobrycon spp.), que representan 21.7\%, 21.7\% y 12\%, respectivamente. Además de los peces, los miembros de la comunidad consumen otros animales, como el pollo de corral (Gallus gallus), el pato (Anatidae) y el cerdo (Sus domesticus). Aunque "prohibido", el tracajá (Podocnemis unifilis) fue mencionado como el animal que se utiliza esporádicamente como alimento. Si bien la agricultura se identifica como la principal actividad económica y de subsistencia que se realiza en las comunidades, la pesca es de fundamental importancia en la vida de los miembros de la comunidad, ya que se practica durante todo el año para obtener alimentos y, en algunos casos, para su comercialización.

Descriptores: comunidad ribereña, represas, Amazonas.

\section{INTRODUÇÃO}

A região amazônica apresenta um complexo cultural que envolve um conjunto tradicional de valores, crenças e modos de vida que delinearam a sua organização social, englobando conhecimentos, práticas e usos dos recursos naturais originários da floresta, rios, lagos, ambientes de várzeas e terras firmes. Tais conhecimentos e modos de vida são de origem predominantemente indígena e foram sendo incorporados e adaptados por colonizadores e povoadores ao longo do tempo (MENDONÇA et al., 2007; LIMA et al., 2015).

Os ribeirinhos ou caboclos amazônidas vivem às margens de rios, lagos, igarapés e várzeas, onde desenvolvem suas atividades, tiram seu sustento, obtêm alimento e se locomovem. Essas atividades são impostas pelo pulso anual das inundações que controlam a vida da população ribeirinha e explicam a maior parte das adaptações da fauna e da flora (MENDONÇA et al., 2007; SILVA e NODA, 2016).

Os ribeirinhos amazônidas utilizam os recursos naturais de forma múltipla, envolvendo a agricultura, pesca, extrativismo de produtos florestais e faunísticos, além da pecuária de pequena escala, em alguns casos, de onde obtêm renda e alimento. Dentre tantas atividades, a agricultura, a pesca, a coleta e a caça de subsistência têm sido apontadas como as principais atividades produtivas dos ribeirinhos e outras populações tradicionais amazônicas (OLIVEIRA et al., 2013; BRAGA e REBÊLO, 2015).

De acordo com Braga e Rebêlo (2015) e Laurido e Braga (2018) o peixe é a principal fonte de proteína animal para os ribeirinhos e as taxas de consumo de pescado na Amazônia são estimadas em torno de 500g/dia, demostrando a alta dependência alimentar e econômica por essas populações. A carne da caça costuma ser, depois do peixe, o alimento 
proteico mais importante da população ribeirinha (BRAGA e REBÊLO, 2015).

Diante das informações acima descritas, e partindo do pressuposto de que há poucas informações acerca das atividades desenvolvidas por populações ribeirinhas em reservatórios da Amazônia, este estudo visa contribuir com informações acerca da utilização dos recursos naturais em cinco comunidades à montante da usina hidroelétrica de Curuá-Una.

\section{MATERIAL E MÉTODOS}

\section{Área de estudo}

O estudo foi desenvolvido nas comunidades Xavier, Vista Alegre do Moju, Porto Alegre, São Francisco do Poraquê e Castanheira, situadas à montante da Usina Hidroelétrica de Curuá-Una, cidade de Mojuí dos Campos, a 70 km ao Sudoeste da cidade de Santarém, no Estado do Pará (Figura 1).

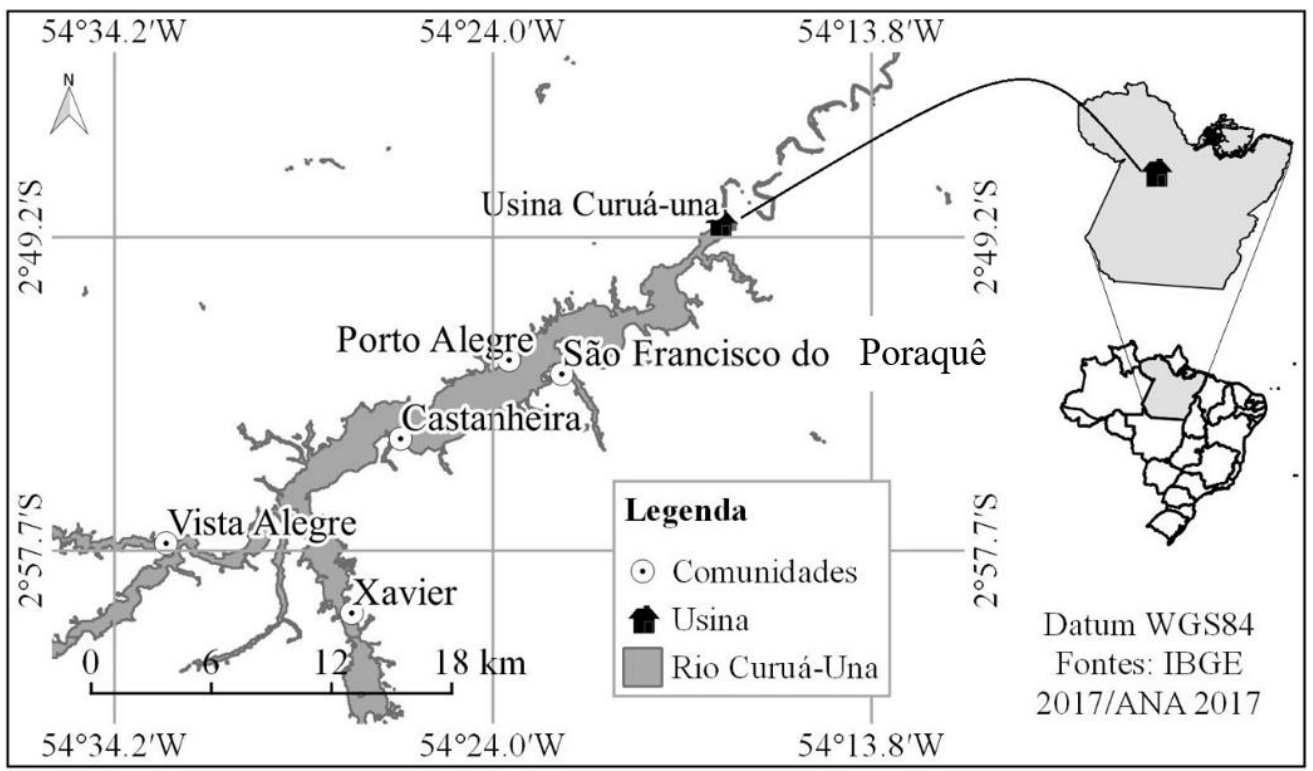

Figura 1. Localização geográfica das comunidades estudadas no entorno da UHE de Curuá-Una, Mojuí dos Campos, Pará. Fonte: Laboratório de Geoinformação e Análise Ambiental (ICTA/UFOPA).

A Usina Hidroelétrica Silvio Braga (UHE Curuá-Una) teve os primeiros estudos objetivando sua construção em 1950 e foi inaugurada em 1977, sendo a primeira represa construída na Amazônia Central. A barragem está localizada no Rio CuruáUna, afluente da margem direita do Rio Amazonas, na Cachoeira do Palhão $\left(2^{\circ} 50^{\prime} \mathrm{S}\right.$; $\left.54^{\circ} 18^{\prime} \mathrm{W}\right)$.

O Rio Curuá-Una é caracterizado como rio de água clara, fundo arenoso, $\mathrm{pH}$ variando de 4,3 a 5,4, situado entre as bacias dos Rios Tapajós e Xingu. Destaca-se tanto pela grande importância como agente gerador de energia elétrica para a população de Santarém, quanto pela sua posição socioeconômica, pois é através dele que as comunidades que vivem em sua margem conseguem se locomover de um local a outro e fazer a comercialização dos produtos agrícolas como arroz, feijão, milho, farinha e outros (SIOLI, 1967; JUNK et al., 1981; ALMEIDA et al., 2003).

\section{Coleta de dados}

coleta de dados se deu através de entrevista semiestruturada, por apresentar possibilidades de 
abertura para novos questionamentos durante sua aplicação, caso haja necessidade (SILVA e BRAGA, 2017). Tais entrevistas seguiram um roteiro pré-estabelecido com o intuito de garantir o máximo no que se referia às informações sobre conhecimentos de recursos faunísticos e suas utilidades.

Foi utilizado o método de "snowball" (BAILEY, 1982) que consiste em chegar à comunidade e procurar por lideranças locais que tenham contato direto e fazem uso de recursos faunísticos e ao final de cada entrevista foi solicitado ao informante que indicasse um (ou mais) morador da comunidade que fosse considerado um especialista nessa atividade perante seus pares. Nesta etapa do trabalho contamos com o apoio do Laboratório de Biologia Ambiental, da Universidade Federal do Oeste do Pará (UFOPA), para realização dos primeiros contatos e deslocamentos por via fluvial.

$\mathrm{O}$ número de entrevistas tentou corresponder, no mínimo, a um especialista de cada família residente nas comunidades e que fizesse uso do conhecimento sobre a fauna local para atividades visando a obtenção de renda e/ou subsistência.

\section{Análise de dados}

Todas as informações coletadas foram digitalizadas em bancos de dados, elaborado em planilhas eletrônica (Excel) e posteriormente analisadas com uso de tabelas dinâmicas e estatística descritiva, explicando os padrões encontrados e procurando por relacionamentos entre as dimensões descritivas, como descritas em Silva e Braga (2017). A forma de análise dos dados obtidos nas entrevistas também envolveu a categorização do conteúdo das respostas como descrito em Braga e Rebelo (2014).

\section{RESULTADOS}

\section{Caracterização dos comunitários e principais atividades desenvolvidas}

Foram realizadas 71 entrevistas com moradores especialistas das cinco comunidades, sendo distribuídas da seguinte maneira: 14 na comunidade Xavier, 3 em Vista Alegre do Moju, 15 em Porto Alegre, 13 em São Francisco do Poraquê e 26 em Castanheira. Dos 71 comunitários entrevistados, 33 são mulheres e 38 homens, com idade média de 43,12 ( $\pm 15,72)$ anos. A procedência natural declarada pelos entrevistados mostrou-se heterogênea, no qual $35 \%$ são provenientes do município de Santarém e/ou comunidades; 35\% do município de Mojuí dos campos, incluindo as comunidades estudadas, e 30\% são provenientes de outros municípios do Pará e de outros estados como Maranhão, Ceará, Amapá, Amazonas e Rio Grande do Sul.

Nas cinco comunidades visitadas, a agricultura apareceu como principal atividade exercida. Dentre os homens, $66 \%$ afirmaram exercer a agricultura para obtenção de renda e alimento, ou seja, se consideram agricultores. Apenas 16\% dos homens consideram-se pescadores, que capturam o pescado para subsistência e esporadicamente para a venda nas próprias comunidades. Os demais eram funcionários públicos (6\%), diaristas (5\%), pecuaristas (5\%) e aposentados (2\%). Em relação às mulheres, $58 \%$ consideram-se donas de casa, $30 \%$ agricultoras. As demais recebem benefício 
do governo (3\%), aposentadas (3\%), agente comunitária de saúde (3\%) e servente (3\%).

Entre os principais produtos obtidos das plantações cultivadas (roças), destacam-se a mandioca, feijão, arroz e milho. A mandioca é usada para a produção de farinha que é consumida juntamente com o peixe nas comunidades, além de ser comercializada por alguns comunitários. Feijão, milho e arroz são cultivados basicamente para o consumo local, assim como o cultivo de frutas, hortaliças, raramente são vendidos. Segundo eles, o milho é destinado também para alimentação de galinhas, criadas em seus quintais.

Durante o estudo, fomos informados que alguns moradores têm exercido a criação de peixes como alternativa para obtenção de alimento. Tal prática foi registrada na comunidade São Francisco do Poraquê, onde o Sr. R.A, agricultor de 39 anos, cria tambaqui (Colossoma macropomum), tambatinga (híbrido tambaqui + pirapitinga Piaractus brachypomus) e tilápia (Oreochromis niloticus) em 3 tanques escavados, com fundo de "alvenaria" (concreto), todos são destinados apenas para o consumo familiar. $\mathrm{Na}$ comunidade Xavier, o Sr. J. E. pecuarista de 52 anos, relatou que possuía um "cercado" para criação de tambaqui, porém, no terceiro ano de produção morreram 500 peixes. Ele acredita que a mortalidade tenha sido ocasionada por alterações na água do reservatório, uma vez que não contava com apoio técnico para tal atividade.

Na comunidade Porto Alegre também foi feito o registro dessa informação, onde um entrevistado disse que cria peixe em "barragem". De acordo com o secretário de Agricultura de Mojuí dos Campos, no início do ano de 2017, a referida secretaria em parceria com a Secretaria de
Desenvolvimento Agropecuário e da Pesca SEDAP fizeram a doação de mais de 52 mil alevinos para algumas comunidades de Mojuí dos Campos, dentre elas, São Francisco do Poraquê.

\section{Caracterização da atividade pesqueira na busca por alimento}

A pesca na região é realizada durante o ano todo. Entretanto, quando perguntados se a quantidade de recursos muda de acordo com a época do ano, os entrevistados expuseram diversas situações. Em alguns casos, afirmam que é difícil falar sobre este assunto, pois o nível da água é controlado pelos técnicos da hidrelétrica, e que o ambiente pode encher ou secar de uma hora para outra.

Alguns entrevistados disseram ter certeza de que o melhor período é no inverno, quando o rio começa a encher "no começo do inverno quando tá enchendo, a água vem chegando os peixes vem junto" (Sr. F., agricultor de $36 \mathrm{a}$. Vista Alegre do Mojú). Outros acreditam que a melhor época para se pescar é no verão, quando o rio está seco. Segundo eles, os peixes ficam concentrados em determinados locais, facilitando a captura.

Em relação aos ensinamentos sobre o exercício da atividade pesqueira $34 \%$ disseram que aprenderam sozinhos, 28\% afirmaram que aprenderam a pescar com o pai, $10 \%$ afirmaram que não pescam, e o restante aprendeu com outros membros da família. Quando questionados sobre a idade com que aprenderam a pescar $84 \%$ disseram que aprenderam quando criança com uma idade média de 9,94 $( \pm 2,44)$ anos, $6 \%$ quando adultos e $10 \%$ afirmaram que não pescam.

Foram registrados 8 tipos de apetrechos utilizados pelos comunitários, sendo estes: 
arma/espingarda de mergulho, arpão, caniço, corrico, espinhel, linha, malhadeira e zagaia. O corrico mencionado por eles constitui-se de uma linha com uma isca artificial e anzol em uma das extremidades, presa a um suporte de madeira. Os comunitários relataram que além da isca artificial, também costumam utilizar "piabas" (caracídeos) como iscas nos corricos para realizar a pesca do tucunaré (Cichla spp.). Os moradores também praticam a pesca de mergulho, na qual utilizam a "arma ou espingarda", uma espécie de arpão impulsionado por liga de soro, construída por eles próprios e, em alguns casos, fazem uso de máscaras de mergulho e lanterna.

Os entrevistados relataram que costumam fazer "seva com casca de mandioca" para pescar. Essa prática consiste pegar as cascas de mandioca resultantes do processo de fabricação de farinha e joga-las no rio, geralmente na frente das próprias residências, onde os mesmos costumam sentar e pescar com caniço, como foi mencionado nas seguintes palavras: "Joga a casca da mandioca na água e pesca com anzol"' (Sra. G. K., dona de casa de 30 a. Porto alegre).

Dentre as artes de pesca mencionadas destacam-se a malhadeira (35\%), seguida da linha de mão ou linha solta (34\%). Em relação ao uso da malhadeira, uma moradora da comunidade Castanheira mencionou que a realização da pesca com malhadeira é feita cercando algum ponto no rio e batendo com as mãos na água (por isso essa pesca também é denominada de "bate-pau", "batição" ou "bate-vara") acaba forçando os peixes a se deslocarem em direção à rede, facilitando sua captura: "Cerca com malhadeira e bate na água com as mãos e os peixes se engatam na malhadeira. A gente já sabe os pontos certos dos peixes" (Sra. E., 40 a., agricultora).

\section{Recursos faunísticos utilizados como alimento}

Foram descritas 35 espécies de vertebrados (peixes, mamíferos, quelônios e aves) usados como alimento nas comunidades estudadas. Maior destaque foi para os peixes com 25 espécies citadas (Tabela 1), das quais o tucunaré (Cichla spp.), o charutinho (Hemiodus spp.) e a piranha (Serrasalmus spp.; Pristobrycon spp.) se sobressaíram com 21,7\%, 21,7\% e 12\%, das respectivas citações. O consumo de peixe per capita na região chega a $360 \mathrm{~g} / \mathrm{dia}$, que juntamente com a farinha de mandioca são os itens mais consumidos nas comunidades visitadas.

A importância do rio Curuá-Una como local fornecedor de proteína animal também pôde ser verificada em pelo menos duas comunidades, ao confirmarem a ocorrência de outros animais usados como alimentos, apesar de "proibidos". $\mathrm{Na}$ comunidade Porto Alegre, uma moradora afirmou que seus filhos faziam a captura de tracajá (Podocnemis unifilis).

Em outra entrevista, na mesma comunidade um informante, falando de alimentos, lembrou que lá existem peixe-boi (Trichechus inunguis) e tracajá (Podocnemis unifilis), mas que sua captura não é permitida. Essa informação também foi registrada na comunidade Castanheira, onde também foi mencionada a tartaruga ( $P$. expansa), que tem a captura proibida. Nesta região ocorreu uma redução na quantidade desses animais "de casco" devido a sua exploração para a venda pois, de acordo com os entrevistados, houve muita perseguição em cima desses recursos. 
Tabela 1. Lista de peixes citados pelos moradores.

\begin{tabular}{|c|c|c|}
\hline Ordem / Família & Nome científico & Nome comum \\
\hline \multicolumn{3}{|l|}{ Osteoglossiformes } \\
\hline Arapaimatidae & Arapaima gigas (Schinz, 1822) & Pirarucu \\
\hline \multicolumn{3}{|l|}{ Characiformes } \\
\hline Anastomidae & $\begin{array}{l}\text { Schizodon spp. } \\
\text { Leporinus spp. } \\
\text { Anostomoides sp.; Schizodon spp. }\end{array}$ & $\begin{array}{l}\text { Aracu } \\
\text { Aracu cabeça gorda } \\
\text { Piau }\end{array}$ \\
\hline Characidae & $\begin{array}{l}\text { Anostomolaes sp.; Schizoaon spp. } \\
\text { Colossoma macropomum (Cuvier, 1818) } \\
\text { Piaractus brachypomus (Cuvier, 1818) }\end{array}$ & $\begin{array}{l}\text { Tambaqui } \\
\text { Pirapitinga }\end{array}$ \\
\hline & $\begin{array}{l}\text { Triportheus spp. } \\
\text { Não identificado }\end{array}$ & $\begin{array}{l}\text { Sardinha } \\
\text { Piaba }\end{array}$ \\
\hline Serrasalmidae & $\begin{array}{l}\text { Mylossoma spp.; Myleus spp. } \\
\text { Serrasalmus spp.; }\end{array}$ & $\begin{array}{l}\text { Pacu } \\
\text { Piranha }\end{array}$ \\
\hline Acestrorhynchidae & Acestrorhynchus spp. & Cangoia \\
\hline Curimatidae & Vários gêneros & Branquinha \\
\hline Prochilondotidae & $\begin{array}{l}\text { Prochilodus nigricans (Agassiz, 1829) } \\
\text { Semaprochilodus spp. }\end{array}$ & $\begin{array}{l}\text { Curimatã } \\
\text { Jaraqui }\end{array}$ \\
\hline Hemiodontidae & Hemiodus spp. & Charutinho \\
\hline Erythrinidae & $\begin{array}{l}\text { Hoplias malabaricus (Bloch, 1794) } \\
\text { Hoplerythrinus unitaeniatus (Spix \& Agassiz, } \\
1829)\end{array}$ & $\begin{array}{l}\text { Traíra } \\
\text { Jeju }\end{array}$ \\
\hline Siluriformes & & \\
\hline Loricariidae & Pterygoplichthys spp. & Acari \\
\hline Pimelodidae & $\begin{array}{l}\text { Pseudoplatystoma punctifer (Castelnau, 1855) } \\
\text { Brachyplatystoma rousseauxii (Castelnau,1855) }\end{array}$ & $\begin{array}{l}\text { Surubim } \\
\text { Dourada }\end{array}$ \\
\hline $\begin{array}{l}\text { Auchenipteridae } \\
\text { Cichliformes }\end{array}$ & Ageneiosus spp. & Mandubé/ Boca larga \\
\hline Cichlidae & $\begin{array}{l}\text { Astronotus spp. } \\
\text { Vários Gêneros } \\
\text { Cichla spp. } \\
\text { Crenicichla sp. }\end{array}$ & $\begin{array}{l}\text { Carauaçú } \\
\text { Cará } \\
\text { Tucunaré } \\
\text { Jacundá }\end{array}$ \\
\hline
\end{tabular}

Verificamos in loco que os comunitários consomem outros animais, como galinha caipira (Gallus gallus) e seus ovos, pato (Anatidae) e porco (Sus domesticus), que são criados em seus quintais. Todos os entrevistados relataram que produtos como carne bovina, frango, produtos industrializados (enlatados, calabresa e mortadela), e até mesmo peixes são comprados nos municípios de Santarém e Mojuí dos Campos, ou em pequenas tavernas nas próprias comunidades.

\section{Atividade de caça para obtenção de alimento}

No que concerne à caça, $42 \%$ dos entrevistados afirmaram que costumam caçar para obter alimento. Foram identificadas 6 espécies de mamíferos e apenas 2 de quelônio. Dentre estes, destacou-se o tatu (Dasypus sp.) (21\%), a paca (Agouti paca, Linnaeus, 1758) (19\%) e o veado (Mazama sp.) (12\%).

A carne de caça é bastante apreciada por eles. No entanto, se mostraram receosos em falar sobre caça e no decorrer das entrevistas, afirmando que só consumiam se algum vizinho doasse e sempre preocupados em saber se as informações coletadas não seriam para o Instituto Brasileiro do Meio Ambiente e dos Recursos Naturais Renováveis (IBAMA) ou para a polícia, demonstrando certo receio. Provavelmente esse comportamento foi 
resultado de alguns acontecimentos recentes na região pois, segundo o secretário de meio ambiente de Mojuí dos Campos, pouco antes das nossas visitas às comunidades houve apreensão de madeira na região, por parte do IBAMA.

Do total de entrevistados, 58\% afirmaram que não caçam, sendo que a justificativa dada por eles está relacionada com a diminuição na quantidade desses animais na floresta, devido desmatamento e queimadas, tornando difícil desenvolver essa atividade.

\section{Calendário etnoecológico das comunidades}

Com base nas informações repassadas pelos comunitários foi possível elaborar um calendário etnoecológico contendo os alimentos que são cultivados e consumidos, de acordo com a época de chuva e estiagem na região (quadro 1).

Quadro 1. Calendário etnoecológico das comunidades Xavier, Vista Alegre do Moju, Porto Alegre,

São Francisco do Poraquê e Castanheira.

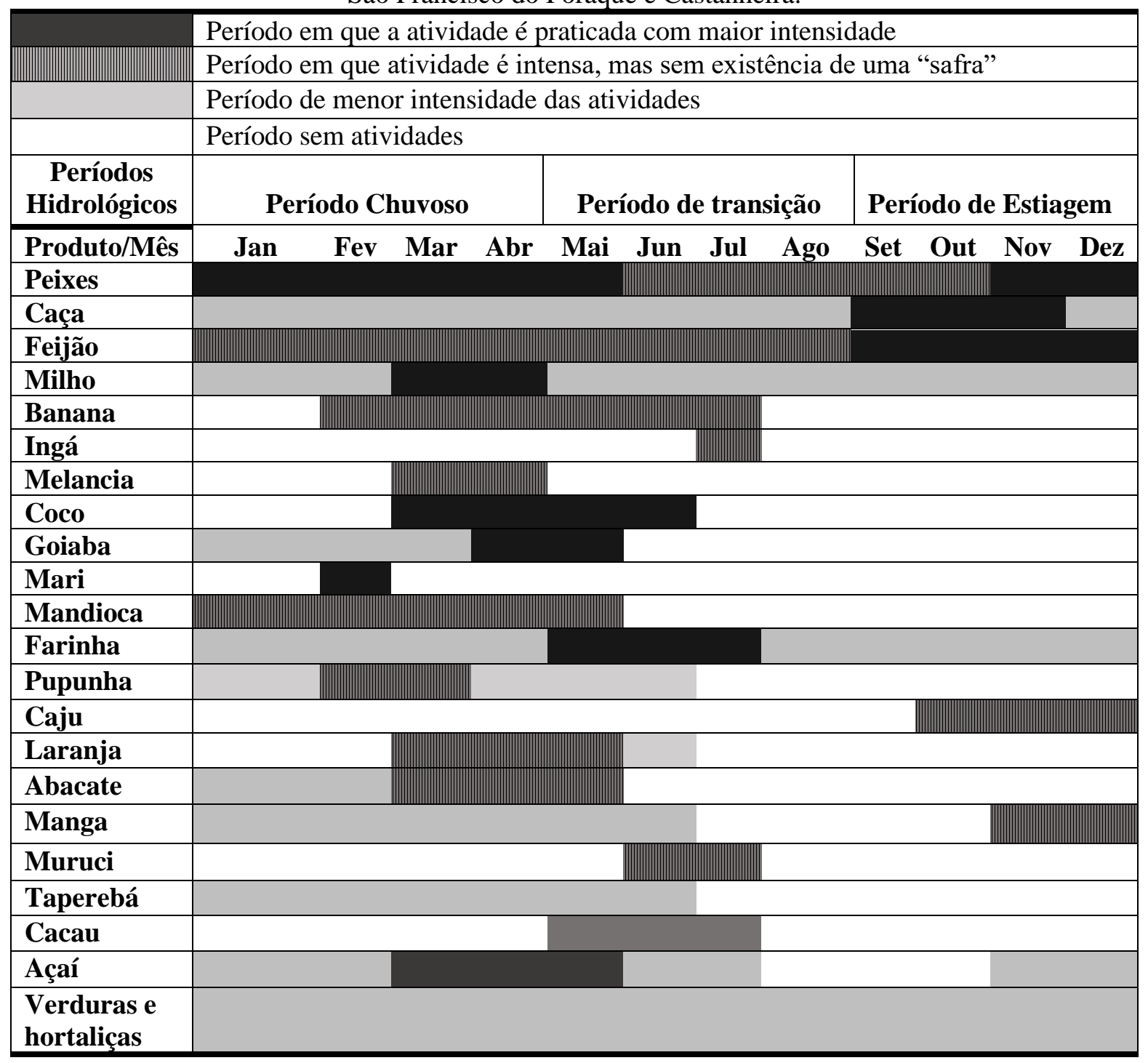


Nota-se que o peixe é capturado e consumido durante o ano todo e a pesca se torna mais intensa entre os meses de novembro a maio, época em que as chuvas se tornam mais frequentes. A caça também é realizada durante o ano todo, porém é mais acentuada no período menos chuvoso, quando também ocorre uma maior produção de feijão.

A farinha de mandioca também é consumida durante o ano todo, sendo que sua maior produção ocorre entre os meses de maio a julho. Os comunitários também costumam cultivar e consumir frutas, verduras, legumes e hortaliças, de acordo com as épocas do ano e a disponibilidade.

\section{O uso terapêutico dos recursos}

\section{faunísticos}

Cerca de 59\% dos entrevistados forneceram informações sobre zooterapia e $41 \%$ afirmaram não ter conhecimento sobre este assunto. Registrou-se pelo menos 25 animais indicados para tratamento de enfermidades, dos quais 7 são peixes (Tabela 2).

Apesar do conhecimento que possuem sobre animais utilizados como recurso terapêutico, bem como o modo de preparo destes, a maioria dos entrevistados $(91,5 \%)$ afirmou não fazer mais uso dos mesmos, referindo-se a esta prática como algo que era comum aos seus pais e avós.

\section{Percepções sobre o quantitativo dos recursos}

\section{faunísticos}

Quando questionados sobre mudanças no quantitativo de recursos faunísticos, os entrevistados deram maior ênfase nas informações sobre os peixes consumidos nas comunidades. Desta forma, a maioria dos entrevistados (93\%) afirmou que atualmente existe menos peixe do que há 22 anos, como podemos ver no exemplo a seguir: "Antigamente era mais fácil, 22 anos atrás era muito bom de peixe. Hoje pra pegar 10, 15 tem que ralar" (Sr. R., agente de saúde, 53 anos, Comunidade Xavier).

Os entrevistados apontaram diversos fatores responsáveis pelas mudanças no quantitativo de animais, tais como o aumento populacional nas comunidades, grande quantidade de pescadores de fora pescando para vender (de outras comunidades e municípios), alterações no nível de água do reservatório, pesca de mergulho, uso da malhadeira, inexistência do período do defeso pra essa região e uso de agrotóxicos em plantações nas proximidades das comunidades.

Quando interrogados se os recursos existentes na região poderiam acabar, as respostas foram diversas. Alguns moradores afirmaram que depende dos próprios comunitários, os quais deveriam denunciar aos órgãos competentes a presença de pescadores de fora no reservatório. Outros acreditam que pode acabar porque trata-se de um ambiente represado, não existe o período do defeso no reservatório e o consumo local é muito grande.

Sobre a presença de pescadores de outras comunidades e municípios como Santarém, por exemplo, aparece o seguinte argumento: "Sim. Se não tiver uma regra, uma lei pra desova. Por exemplo, o tucunaré se pegar os dois, os outros peixes comem os filhos, 
aí não tem como crescer. Já pescaram muito.

Tem muitas pessoas de fora que pescam pra vender" (Sr. J. J., 56 anos, agricultor, comunidade Porto Alegre).

Tabela 2. Animais indicados para utilização medicinal nas comunidades do entorno da UHE de

Curuá-Una.

\begin{tabular}{|c|c|c|c|c|}
\hline \multicolumn{5}{|c|}{ MAMÍFEROS } \\
\hline Taxonomia & Nome comum & $\begin{array}{l}\text { Parte } \\
\text { utilizada }\end{array}$ & Pra que serve & Como faz \\
\hline $\begin{array}{l}\text { Tapirus terrestris } \\
\text { (Linnaeus 1758) }\end{array}$ & Anta & Banha & $\begin{array}{l}\text { Inflamação e } \\
\text { inchaço }\end{array}$ & Passa no local \\
\hline $\begin{array}{l}\text { Cebus apella } \\
\text { (Linnaeus, 1758) }\end{array}$ & Macaco prego & Banha & $\begin{array}{l}\text { Tireoide } \\
\text { Desmentidura }\end{array}$ & $\begin{array}{l}\text { Passa no pescoço } \\
\text { Faz massagem }\end{array}$ \\
\hline $\begin{array}{l}\text { Hydrochoerus hydrochaeris } \\
\text { (Linnaeus, 1766) }\end{array}$ & Capivara & Osso & Reumatismo & Torra e faz chá \\
\hline \multirow[t]{6}{*}{$\begin{array}{l}\text { Agouti paca } \\
\text { (Linnaeus, 1766) }\end{array}$} & Paca & Fel (bile) & $\begin{array}{l}\text { Problema no } \\
\text { estomago, } \\
\text { câncer, diabetes } \\
\text { e pressão alta }\end{array}$ & $\begin{array}{l}\text { Toma misturado } \\
\text { no café ou chá }\end{array}$ \\
\hline & & & $\begin{array}{l}\text { Puxar estrepe } \\
\text { (espinho) e } \\
\text { ferimentos }\end{array}$ & $\begin{array}{l}\text { Mistura com } \\
\text { álcool pra não } \\
\text { apodrecer e } \\
\text { passa no local }\end{array}$ \\
\hline & & $\begin{array}{l}\text { Pele (parte } \\
\text { de dentro do }\end{array}$ & $\begin{array}{l}\text { Carne crescida } \\
\text { no olho }\end{array}$ & $\begin{array}{l}\text { Passa por cima } \\
\text { do olho fechado }\end{array}$ \\
\hline & & couro) & $\begin{array}{l}\text { Para não sentir } \\
\text { dor no primeiro } \\
\text { parto }\end{array}$ & $\begin{array}{l}\text { Tomar algumas } \\
\text { gotas misturada } \\
\text { em chá }\end{array}$ \\
\hline & & & Leishmaniose & $\begin{array}{l}\text { Coloca em cima } \\
\text { da ferida }\end{array}$ \\
\hline & & Banha & Cicatrizante & $\begin{array}{l}\text { Passa no local } \\
\text { enfermo }\end{array}$ \\
\hline $\begin{array}{l}\text { Tayassu pecari } \\
\text { (Link, 1795) }\end{array}$ & Porco do mato & Presa (dente) & Pneumonia & Torra e faz chá \\
\hline $\begin{array}{l}\text { Didelphis marsupialis } \\
\text { (Linnaeus, 1758) }\end{array}$ & Mucura & Banha & Dor de ouvido & $\begin{array}{l}\text { Pinga dentro do } \\
\text { ouvido }\end{array}$ \\
\hline Nasua sp. & Quati & $\begin{array}{l}\text { Genitália } \\
\text { masculina }\end{array}$ & $\begin{array}{l}\text { Estimulante } \\
\text { sexual }\end{array}$ & $\begin{array}{l}\text { Torra pra fazer } \\
\text { chá }\end{array}$ \\
\hline \multirow[t]{2}{*}{ Dasypus sp. } & Tatu & Rabo & Dor de ouvido & $\begin{array}{l}\text { "Cutuca" o } \\
\text { ouvido com } \\
\text { cuidado }\end{array}$ \\
\hline & & Fel (bile) & Diabetes & $\begin{array}{l}\text { Põe pra secar no } \\
\text { sol e faz umas } \\
\text { bolinhas tipo }\end{array}$ \\
\hline
\end{tabular}


uma pílula e

toma

Mijo (Urina) Dor de ouvido $\quad$ Tira a bexiga do

tatu morto e
pinga algumas
gotas dentro do
ouvido

Banha Dor de ouvido Pinga algumas gotas dento do ouvido

Casco Problemas no Torra e faz chá

Myrmecophaga sp

Trichechus inunguis

manduá

estomago

Rabo

Derrame

Queima e faz chá

(Natterer, 1883)

Peixe-Boi Banha

Reumatismo

Passa no corpo

\begin{tabular}{|c|c|c|c|c|}
\hline \multicolumn{5}{|c|}{ AVES } \\
\hline $\begin{array}{l}\text { Gallus gallus } \\
\text { (Linnaeus, 1758) }\end{array}$ & Galinha & Banha & Gripe & $\begin{array}{l}\text { Toma misturado } \\
\text { com mel }\end{array}$ \\
\hline $\begin{array}{l}\text { Crax fasciolata } \\
(\text { Spix, 1825) }\end{array}$ & Mutum & Osso/Crista & Pneumonia & Faz chá e toma \\
\hline
\end{tabular}

\begin{tabular}{|c|c|c|c|c|}
\hline \multicolumn{5}{|c|}{ PEIXES } \\
\hline $\begin{array}{l}\text { Arapaima gigas } \\
\text { (Cuvier, 1829) }\end{array}$ & Pirarucu & Banha & Asma & $\begin{array}{l}\text { Toma a banha } \\
\text { pura }\end{array}$ \\
\hline Hoplias malabaricus & Traíra & Banha & Dor de ouvido & Usa em gotas \\
\hline (Bloch,1794) & & Banha & Surdez & Usa em gotas \\
\hline \multirow[t]{2}{*}{$\begin{array}{l}\text { Electrophorus electricus } \\
\text { (Linnaeus, 1766) }\end{array}$} & Poraquê & Banha & Inflamação & $\begin{array}{l}\text { Passa no local } \\
\text { enfermo }\end{array}$ \\
\hline & & Banha & Reumatismo & Passa no corpo \\
\hline $\begin{array}{l}\text { Pseudoplatystoma punctifer } \\
\text { (Castelnau, 1855) }\end{array}$ & Surubim & Banha & Cicatrizante & $\begin{array}{l}\text { Passa no local } \\
\text { afetado }\end{array}$ \\
\hline $\begin{array}{l}\text { Colossoma macropomum } \\
\text { (Cuvier, 1818) }\end{array}$ & Tambaqui & Banha & Amolecer dente & $\begin{array}{l}\text { Passa um } \\
\text { pouquinho no } \\
\text { dente/gengiva }\end{array}$ \\
\hline $\begin{array}{l}\text { Serrasalmus rhombeus } \\
\text { (Linnaeus, 1766) }\end{array}$ & Piranha Preta & Banha & Conjuntivite & $\begin{array}{l}\text { Tira a banha e } \\
\text { pinga no olho }\end{array}$ \\
\hline \multicolumn{5}{|c|}{ REPITILIA } \\
\hline \multirow[t]{2}{*}{ Chelonoidis sp. } & Jabuti & Banha & Rasgadura & $\begin{array}{l}\text { Passa no local } \\
\text { afetado }\end{array}$ \\
\hline & & Casco & Ferida braba & $\begin{array}{l}\text { Queima até virar } \\
\text { pó e coloca em } \\
\text { cima da ferida }\end{array}$ \\
\hline $\begin{array}{l}\text { Caiman crocodilus } \\
\text { (Linnaeus, 1758) }\end{array}$ & Jacaré-tinga & Banha & Bronquite & Toma pura \\
\hline \multirow[t]{2}{*}{$\begin{array}{l}\text { Melanosuchus niger } \\
\text { (Spix, 1825) }\end{array}$} & Jacaré & Banha & Reumatismo & $\begin{array}{l}\text { Passa no local } \\
\text { afetado }\end{array}$ \\
\hline & & & Asma & $\begin{array}{l}\text { Faz massagem } \\
\text { no corpo e toma }\end{array}$ \\
\hline
\end{tabular}

Derrame 
Toma misturado com chá e passa no copo

Couro

Sucuriju

(Linnaeus, 1758)

(Linnaeus, 1758)

Lachesis muta (Linnaeus, 1766)
Banha

Artrose e

reumatismo

Derrame

Mistura com cachaça e toma

Faz chá e fricção

no corpo

Cicatrizar Passa no local

cortes, cirurgias, enfermo

inchaço,

infecções,

quebraduras

Reumatismo Passa no local e

faz massagem

Banha Reumatismo Passa no local

Banha Ferimentos Passa no local

afetado

Passa no local

afetado

\section{DISCUSSÃO}

O quantitativo de moradores residentes nas comunidades próximas da Usina Hidroelétrica de Curuá-Una e que se reconhecem como profissionais da pesca é baixo se comparado com o que já foi registrado em outros reservatórios do país, como em Tucuruí, no Pará, por exemplo, onde há um número significativo de pescadores artesanais atuando na atividade da pesca (CINTRA et al., 2013; SANTANA et al., 2014).

Essa diferença pode estar associada com a visão que os moradores das comunidades no entorno da UHE de Curuá-Una têm em relação àquilo que pode ser considerado como sendo trabalho de fato. Na concepção deles a agricultura é considerada como um trabalho, uma profissão de fato. No entanto, a importância da atividade pesqueira para obtenção de renda é inquestionável, como podemos observar na seguinte frase citada pelo Sr. R., agricultor de 73 anos, morador da comunidade Porto Alegre: "O pessoal pesca pra vender e comprar as outras coisas. Eu vejo poucas pessoas plantando". Fato semelhante a este foi observado por Silva e Braga (2016) entre os moradores da comunidade Surucuá, na Reserva Extrativista TAPAJÓS-ARAPIUNS, município de Santarém, Pará, onde a agricultura, como profissão, aparece como uma atividade mais valorizada e com maior prestígio se comparado à pesca.

Apesar de apenas uma minoria (16\%) dos homens entrevistados ter se declarado pescador, quando perguntados sobre a atividade realizada para obtenção de alimentos, praticamente todos mencionaram a pesca, evidenciando desta forma, a importância desta atividade como meio de subsistência para as comunidades do entorno da UHE de Curuá- 
Una. Comportamento parecido já foi observado em outras comunidades amazônicas, onde além da pesca, os pescadores praticam a agricultura para fins de subsistência e comercial (BRAGA e REBÊLO, 2015; SILVA e BRAGA, 2016).

Em relação às mudanças na quantidade de recursos de acordo com a época do ano podese afirmar que de fato os procedimentos operacionais dos reservatórios controlam o regime hidrológico, fazendo com que este seja altamente variável (AGOSTINHO et al., 2007).

Os resultados obtidos neste estudo sobre a pesca do tucunaré (Cichla spp.) apresentam congruência com as atividades de pesca na UHE de Tucuruí, no Pará, onde os pescadores também afirmaram que as melhores épocas para se capturar essa espécie é nas águas baixas, uma vez que na época de cheia os peixes vão a locais de difícil captura (ALVES e BARTHEM, 2008). A informação repassada pelos entrevistados que acreditam que o melhor período para se pescar é no inverno, difere do que é observado em ambientes de rios livres e sem a presença de barragens, como foi registrado para a região do alto Rio Negro, no estado do Amazonas, onde o período do inverno (cheia) é considerado mais difícil para a captura de peixes (SILVA, 2011).

Apesar de muitos entrevistados terem afirmado que aprenderam a pescar sozinhos apenas observando outras pessoas pescando, uma quantidade significativa indicou o pai como responsável sobre ensinamentos acerca da atividade pesqueira, evidenciando a figura masculina na atividade. Tal situação já foi verificada em outras localidades da Amazônia, como na comunidade Surucuá, no Rio Tapajós, e Coaracy Nunes, no Amapá (OLIVEIRA et al., 2013; SILVA e BRAGA, 2017).

Os apetrechos utilizados e mencionados neste estudo também foram verificados em outras comunidades amazônicas (BRAGA et al., 2008; SILVA e BRAGA, 2016; ZACARDI et al., 2017), bem como em outros reservatórios pelo país, onde a malhadeira/rede de emalhe aparece como o principal apetrecho utilizado (SCHORK et al., 2012; OLIVEIRA et al., 2013; CINTRA et al., 2013; FLEXA et al., 2016;). A utilização do corrico também foi verificada na UHE de Tucuruí, na pesca artesanal dos tucunarés (ALVES e BARTHEM, 2008) e em Balbina (SANTOS e OLIVEIRA Jr., 1999). Entre os pescadores da Floresta Nacional do Amapá a utilização da piaba como isca também foi verificada, mostrando que não é uma prática exclusiva da região em estudo (BRANDÃO e SILVA, 2008).

A prática do mergulho, utilizando instrumentos como arpões, para a captura de peixes tem sido observada em outros reservatórios pelo país, apesar de ser considerada como uma prática que motiva o aparecimento de conflitos entre os próprios pescadores. Em Tucuruí, por exemplo, a pesca de mergulho utilizando arpão foi apontada pelos pescadores artesanais como sendo ilegal e com alto poder de pesca (CINTRA et al., 2011). O mesmo é visto para a Usina Hidrelétrica Peixe Angical, no alto Rio Tocantins (SOUZA et al., 2016).

O tipo de pesca conhecida como "batepau", "batição" ou "bate-vara", mencionada neste estudo, também foi observado entre os pescadores da RESEX Marinha Caeté- 
Taperaçu, no Pará, e no alto rio Negro. A mesma consiste em deslocar os peixes de seus refúgios através da produção de barulho na água provocado por "batidas" repetitivas, o que pode resultar na fuga dos peixes das áreas de pesca (BARBOZA e PEZZUTI, 2011; SILVA, 2011).

Assim como registrado em outros trabalhos, em diversas comunidades da região amazônica, o peixe e a farinha de mandioca são os itens mais consumidos nas comunidades estudadas e reforçam a importância do peixe como fonte de proteína animal (MURRIETA et al., 2008; SILVA et al., 2014; SILVA e BRAGA, 2017).

Estudos realizados em diferentes pontos da Amazônia onde houve construções de hidrelétricas, indicaram que o tucunaré foi uma das espécies mais capturadas, como nos reservatórios de Samuel, no Estado de Rondônia (SANTOS, 1995), em Tucuruí, no Pará (FLEXA et al., 2016), em Coaracy Nunes, no Amapá (OLIVEIRA et al., 2013), e em Balbina, no Amazonas (SANTOS e OLIVEIRA JR., 1999). De acordo com Santos e Santos (2005), o tucunaré é uma espécie sedentária, que além da pesca comercial, é bastante visada pela pesca esportiva, que tem se intensificado em reservatórios de hidrelétricas na Amazônia.

Diferente do que foi verificado neste estudo, a captura de quelônios é bastante comum em outros pontos da Amazônia, onde estes animais exercem importantes papeis na vida dos comunitários, como foi registrado na RESEX do Baixo Juruá, no estado do Amazonas, por Braga e Rebêlo (2015), onde a captura de quelônios é bastante comum tanto para obtenção de alimento quando de renda, assim como no Parque Nacional do Jaú, também no Amazonas, onde realiza-se a pesca para subsistência e comercial de pequena escala (REBÊLO et al., 2005). Diversos estudos sobre quelônios em comunidades amazônicas têm demonstrado que esses animais têm sofrido pressão humana há muito tempo, ocasionando a redução na quantidade de seus estoques (SMITH, 1979; REBÊLO e PEZUTTI, 2000; ATAIDES et al., 2010; BARBOZA, 2012; BARROSO e MOURA, 2016).

Assim como nas comunidades abordadas nesse estudo, a prática da caça para fins alimentícios também foi verificada em outros reservatórios do Brasil, como em Coaracy Nunes, no Amapá (OLIVEIRA et al., 2013); em Tucuruí, no Pará (CAMARGO, 2002), e em Balbina, no Amazonas (BANDRÃO, 2010). Esta atividade apresenta grande importância no período chuvoso, quando o nível das águas do rio aumenta, dificultando o acesso ao pescado devido sua maior dispersão nas áreas alagadas (FIGUEIREDO e BARROS, 2016).

Na hidrelétrica de Tucuruí, o tatu e a paca também aparecem entre os animais de caça mais consumidos (CAMARGO, 2002). A caça desses animais também foi verificada em outros estados brasileiros. No Estado do Acre, no Seringal Cachoeira e Filipinas, o tatu e a paca também aparecem entre os animais mais caçados nesta região amazônica (ROSAS e DRUMOND, 2007; FUCCIO et al., 2003). Na Resex do Baixo Juruá, no Amazonas, a paca também aparece entre os mais animais mais 
caçados, como verificado por Braga e Rebêlo (2015).

Andriguetto-Filho et al. (1998) explicam que o receio dos entrevistados em assumir a atividade de caça perante $o$ entrevistador e sofrer possíveis consequências negativas podem estar relacionadas à existência de conflitos ambientais, podendo desta forma refletir em falsas declarações, como observaram em seu estudo na Área de Proteção Ambiental de Guaraqueçaba, no Estado do Paraná. É bem possível que isso pode ter acontecido nas referidas comunidades deste estudo.

A percepção sobre mudanças na quantidade de animais de caça foi observada em outras comunidades pelo país (SILVA, 2011; TERRA e REBÊLO, 2005; NASCIMENTO e GUERRA, 2016). Assim como mencionado pelos comunitários entrevistados neste estudo, em trabalho realizado por Pereira e Schiavetti (2010) nas comunidades indígenas "Tupinambá de Olivença", na Bahia, os caçadores relataram que o desmatamento e o excesso de caça são os principais motivos da redução desses animais. De acordo com Ribeiro et al. (2007) a ação antrópica, caracterizada especialmente pela caça, exploração madeireira e o desmatamento, exerce efeitos variados sobre as densidades de espécies animais, podendo levá-las a extinção.

Mesmo em locais onde o peixe é descrito como a principal proteína animal consumida, nem sempre ele está disponível ao consumidor, o que leva os comunitários a adquirirem outros alimentos, como descrevem Silva et al. (2014) para o município de Juruá, no Amazonas, onde o peixe é o alimento mais consumido no município, mas também ocorre o consumo de alimentos industrializados. Oliveira et al. (2013) verificaram comportamento semelhante em comunidades do entorno do reservatório de Coaracy Nunes, no Amapá, e relacionaram essa situação com o aumento da renda da população de baixo poder aquisitivo que estimulou o comércio em áreas onde não havia estabelecimentos com gêneros alimentícios, aliado ao contato com as sociedades urbanas.

Nascimento e Guerra (2016) em trabalho realizado em uma comunidade quilombola do baixo Acaraqui, em Abaetetuba, no Pará, registraram que a chegada da energia elétrica aliada a uma maior participação no comercio local e à inclusão de benefícios sociais na renda das famílias permitiram o aumento no poder aquisitivo local, o que consequentemente ocasionou mudanças nos hábitos alimentares das famílias. Possivelmente a mesma situação deve ter ocorrido na área de estudo deste trabalho.

Comparando os resultados deste trabalho com outros realizados em diferentes regiões, podemos ver que os peixes sempre estão presentes na zooterapia local. Na Reserva Extrativista do baixo Juruá, no Amazonas Braga e Rebêlo (2015) identificaram o uso zooterápico de 24 animais, sendo seis deles peixes. Na cidade de São Félix, na Bahia, foi registrado o uso de 43 tipos de peixes utilizados na medicina tradicional (ANDRADE e COSTA-NETO, 2005). Em trabalho com os pecadores artesanais do litoral paraense, Barboza et al. (2014) identificaram o uso de 16 etnoespécies de peixes utilizados para fins 
medicinais e, além disso, esses mesmos autores verificaram um comportamento parecido com o que observamos neste estudo, onde a facilidade ao acesso a medicamentos em farmácias e postos de saúde tem contribuído para a perda dos hábitos e costumes tradicionais.

Andrade e Costa-Neto (2005) afirmam que a utilização medicinal de recursos pesqueiros tem implicações importantes na conservação da cultura local e permitem que os recursos zooterapêuticos sejam testados quanto à provável existência de compostos biologicamente ativos. Porém, os resultados obtidos neste trabalho mostram que uma parcela importante da cultura local pode estar sendo perdida, mesmo verificando que os peixes ainda fazem parte do cotidiano local.

O estado da etnoictiologia no Brasil e no exterior demonstra que os pescadores artesanais, tradicionais e indígenas são capazes de acumular, ao longo de suas vidas, um conjunto de conhecimentos referente à biologia e à ecologia dos peixes e de transmitir esses conhecimentos às futuras gerações (COSTANETO et al., 2002; BARBOZA et al., 2014). No entanto as mudanças drásticas provocadas no ambiente, como a construção de hidrelétricas, provocam mudanças na estrutura das comunidades ictícas locais e consequentemente trazem perda do conhecimento que havia sido acumulado por pescadores.

Mudanças no quantitativo de recursos pesqueiros também foram verificadas em outros reservatórios no país, como no reservatório de Samuel, no Estado de Rondônia, na Hidrelétrica de Peixe Angical, no alto Rio
Tocantins e em Tucuruí, no Pará, onde também foi verificado que o aumento populacional é um dos fatores responsável pela redução na quantidade de pescado, afetando de forma negativa a vida dos pescadores locais (SANTOS, 1995; SANTOS e OLIVEIRA Jr., 1999; SOUZA et al., 2016; CINTRA et al., 2011; SANTANA et al., 2014; OLIVEIRA et al., 2013; FLEXA et al., 2016).

A diminuição na quantidade de peixes devido as variações no nível de água também foram apontadas para outros reservatórios, como em Coaracy Nunes, no Amapá (OLIVEIRA et al., 2013). Na UHE de Tucuruí, a mudança no ciclo hidrológico do rio Tocantins refletiu sobre as condições naturais do ecossistema e consequentemente na reprodução das espécies de peixes existentes na área (BENTES et al., 2014), o que possivelmente ocorre no entorno da UHE de Curuá-Una.

O uso da malhadeira citado neste trabalho como sendo responsável pela diminuição na quantidade de peixes, também é descrito para comunidade Boca do Arapirí, em Alenquer- $\mathrm{Pa}$, onde a malhadeira foi citada como a principal responsável pela diminuição na quantidade das principais espécies comerciais da região (LAURIDO e BRAGA, 2018).

Em todas as comunidades visitadas a presença de pescadores "de fora" foi citada como um dos principais fatores responsáveis pela redução da quantidade de peixes no reservatório. Isso também foi um fator apontado em outros reservatórios, como em Coaracy Nunes, no Amapá, Tucuruí, no Pará, e 
no reservatório de Furnas, no Estado de Minas Gerais (AZEVEDO-SANTOS et al., 2010; OLIVEIRA et al., 2013; FLEXA et al., 2016).

Uma informação importante registrada na comunidade Castanheira, refere-se a possível contaminação da água do rio por agrotóxicos provenientes da água lixiviada das chuvas que caem nas plantações de soja existentes nas adjacências da comunidade. Informação semelhante a esta foi registrada entre os pescadores que utilizam o reservatório de Furnas, no Estado de Minas Gerais, que acreditam que a redução na quantidade de peixe na região está associada diretamente aos agrotóxicos que são aplicados para matar pragas em lavouras e que são lixiviados para o lago, ocasionando grande mortalidade de peixes (AZEVEDO-SANTOS et al., 2010).

\section{CONCLUSÃO}

Observamos que apesar da agricultura se apresentar como principal atividade desenvolvida pelos moradores da região para obtenção de renda, estes também dependem diretamente da pesca para obtenção de proteína animal. O consumo médio de peixe nas comunidades foi de 360g.dia.pessoa, valores próximos ao que foi registrado em outras regiões da Amazônia.

Além da pesca e agricultura foi possível observar que a caça também é uma atividade importante para obtenção de alimento, sendo que esta torna-se mais intensa no período menos chuvoso, época em que a captura do peixe se torna mais difícil. Apesar disso, registramos um número de espécies capturadas relativamente baixo se comparado com outras comunidades amazônicas. Esse quantitativo baixo pode estar relacionado tanto ao receio que os comunitários apresentaram ao falar deste assunto devido a questões relacionadas com órgãos ambientais quanto à redução na quantidade de animais nas florestas devido a ações antrópicas como queimadas e extração de madeira.

Em relação a utilização de animais como recursos medicinal, apesar de atualmente não fazerem uso destes para este fim, as informações fornecidas mostram que essa prática foi realizada por seus antepassados, que lhes repassaram tais conhecimentos. Desta forma, eles demonstraram um conhecimento parcial sobre o uso medicinal de determinadas espécies, o que demonstra que a alteração do ambiente com a construção de hidrelétrica, trazem mudanças não somente ecológicas e sociais mais também comportamentais e culturais. Isso fica mais evidente no que se refere aos peixes, para os quais foram apresentados um número relativamente baixo usados na zooterapia, quando comparado com outros trabalhos sobre o assunto e em locais com ausência dessas grandes obras.

A diminuição na quantidade de recursos devido à pressão antrópica e alterações no ambiente é um ponto preocupante, sendo necessária a atenção dos órgãos responsáveis. Desta forma, é de fundamental importância que se façam novos estudos na região, contribuindo com informações sobre o ecossistema e o modo de vida dessas populações, a fim de estabelecer um gerenciamento adequado dos recursos. 


\section{REFERÊNCIAS}

AGOSTINHO, A. A.; GOMES, L. C.; PELICICE, F. M. Ecologia e Manejo de Recursos Pesqueiros em Reservatórios do Brasil. Maringá. Eduem, 2007. 501 p.

ALVES, M. C. B.; BARTHEM, R. B. A pesca comercial dos "tucunarés" Cichla spp. (perciformes, cichlidae) no reservatório da UHE-Tucuruí, Rio Tocantins, Pa. Boletim do Instituto de Pesca. v. 34, n.4, p.553-561. 2008.

ANDRADE, J. N.; COSTA-NETO, E. M. Primeiro registro da utilização medicinal de recursos pesqueiros na cidade de São Félix, Estado da Bahia, Brasil. Acta Scientiarium Biological Sciencies. v.27, n.2, p. 177-183. 2005.

ANDRIGUETTO-FILHO, J. M.; KRUGER, A. C.; LANGE, M. B. R. Caça, biodiversidade e gestão ambiental na Área de Proteção Ambiental de Guaraqueçaba, Paraná, Brasil. Biotemas. v.11, n.2, p.133-156. 1998.

AZEVEDO-SANTOS, V. M. de.; COSTANETO, E. M. C.; LIMA-STRIPARI, N. de. Concepção dos pescadores artesanais que utilizam o reservatório de Furnas, Estado de Minas Gerais, acerca dos recursos pesqueiros: um estudo etnoictiológico. Biotemas. v.23, n.4, p.135-145. 2010.

BAILEY, K. D. Methods of social research. The Free Press, McMillan Publishers, New York. 1982.553p.

BARBOZA, R. S. L.; BARBOZA, M. S. L.; PEZZUTI, J. C. B. Aspectos culturais da zooterapia e dieta alimentar de pescadores artesanais do litoral paraense. Fragmentos da Cultura. v.24, n.2, p.253-266. 2014.

BARBOZA, R. S. L. Etnoecologia, pesca e manejo comunitário de quelônios aquáticos na várzea do Baixo Rio Amazonas. 2012. $251 \mathrm{f}$. Tese (Doutorado) Universidade Federal do Pará/UFPA, Centro de Ciências Biológicas, Belém. 2012.

BARBOZA, R. S. L.; PEZZUTI, J. C. B. Etnoictiologia dos pescadores artesanais da Resex Marinha Caeté- Taperaçu, Pará: aspectos relacionados com etologia, usos de hábitat e migração de peixes da família Sciaenidae. Sitientibus série Ciências Biológicas. v.11, n.2, p.133-141. 2011.

BARROSO, W. A.; MOURA, N. A. de. Etnoconhecimento morfológico e ecológico de quelônios (Podocnemis expansa e P. unifilis) em uma comunidade ribeirinha. Biota Amazônica. v.6, n.1, p. 91-95. 2016.

BENTES, E. dos S. A pesca artesanal a jusante da Usina Hidrelétrica (UHE) de Tucuruí, Estado do Pará. Novos Cadernos NAEA. v. 17, n.2, p.167-187. 2014.

BRAGA, T. M. P.; REBÊLO, G. H. Uso da fauna por comunitários da reserva extrativista do Baixo Juruá, Amazonas, Brasil. Papers do NAEA. 347. p.1-25. 2015.

BRAGA, T. M. P.; REBÊLO, G. H. Conhecimento tradicional dos pescadores do baixo rio Juruá: aspectos relacionados aos hábitos alimentares dos peixes da região. Interciência. v.39, n. 9, p. 1-7. 2014.

BRAGA, T. M. P., BARROS, J. F., CHAVES, M. do P. S. Pesca e conflitos socioambientais na Amazônia central: Estudo em uma área com manejo comunitário. Revista de Estudos Amazônicos, SOMANLU. v.7, n. 1, 2008.

BRANDÃO, F. C.; SILVA, L. M. A. da. Conhecimento ecológico tradicional dos pescadores da Floresta Nacional do Amapá. Revista Uakari. v. 4, n.2. p.55-66. 2008.

CAMARGO, S. Q. F. Pesca profissional, dilemas e conflitos no reservatório da UHETucuruí, PA. 139 f. Tese (Doutorado) Centro de Aquicultura, Universidade Estadual Paulista, São Paulo, 2002.

CINTRA, I. H. A.; FLEXA, C. E.; SILVA, M. B. da.; ARAÚJO, M. V. L. F. de.; SILVA, K. C. de A. A pesca no reservatório à jusante da Usina Hidrelétrica de Tucuruí, região Amazônica, Brasil: aspectos biológicos, sociais, econômicos e ambientais. Acta of Fisheries and Aquatic Resources. v.1, n.1, p.57-78. 2013.

CINTRA, I. H. A.; MANESCHY, M. C. A.; MOURÃO, R. do S. N.; OGAVA, M. Pescadores artesanais do reservatório da usina 
hidrelétrica de Tucuruí (Pará, Brasil). Revista de Ciências Agrárias. v.54, n.1, p.61-70. 2011.

COSTA-NETO, E. M.; DIAS, C. V.; MELO, M. N. de. O conhecimento ictiológico tradicional dos pescadores da cidade de Barra, região do médio São Francisco, Estado da Bahia, Brasil. Acta Scientiarium. v.24, n. 2. P. 561-572. 2002.

FLEXA, C. E.; SILVA, K. K., A.; CINTRA, I. H. A. Pescadores artesanais à jusante da usina hidrelétrica de Tucuruí, Amazônia, Brasil. Boletim do Instituto de Pesca. v.42, n.1, p. 221-235, 2016.

FIGUEIREDO, R. A. A. de.; BARROS, F. B. Sabedorias, cosmologias e estratégias de caçadores numa unidade de conservação da Amazônia. Desenvolvimento e Meio ambiente. v.36, p.223-237. 2016.

FUCCIO, H.; CARVALHO, E. F. de.; VARGAS, G. Perfil da caça e dos caçadores no Estado do Acre, Brasil. Revista Aportes Andinos. Movimientos Sociales, Politicas de Seguridad y Democracia. n.6, p.1-18. 2003.

JUNK, W. J.; ROBERTSON, B. A.; DARWICH, A. J.; VIEIRA, I. Investigações limnológicas e ictiológicas em Curuá-Uma, a primeira represa hidrelétrica na Amazônia Central. Acta Amazônica. v.11, n. 4, p. 6809716. 1981.

LAURIDO, S.; BRAGA, T. Uso de malhadeiras na comunidade Boca do Arapirí, Alenquer-Pará. In: V Seminário Internacional em Ciências do Ambiente e Sustentabilidade na Amazônia. Anais do Seminário Internacional em Ciências do Ambiente e Sustentabilidade na Amazônia, v. 5. Manaus: EDUA. 2018.

MENDONÇA, M. S. de.; FRANÇA, J. F.; OLIVEIRA, A. B. de.; PRATA, R. R.; AÑEZ, R. B. da S. Etnobotânica e o saber tradicional. In: FRAXE, T. de. J. P.; PEREIRA, H. dos S.; WITKOSKI, A. C. (Orgs.). Comunidades ribeirinhas amazônicas: modos de vida e uso dos recursos naturais. EDUA, Manaus, AM. 2007. p. 91-105.

MURRIETA, R. S. S.; BAKRI. M. S.; ADAMS, C.; OLIVEIRA, P. S. de S.; STRUMPF, R. Consumo alimentar e ecologia de populações ribeirinhas em dois ecossistemas amazônicos: um estudo comparativo. Revista de Nutrição. v. 21. p. 123-133. 2008.

NASCIMENTO, E. C. do; GUERRA, G. A. D. Do avortado ao comprado: práticas alimentares e a segurança alimentar da comunidade quilombola do baixo Acaraqui, Abaetetuba, Pará. Boletim do Museu Emílio Goeldi. Ciências Humanas. v.11, n.1, p.225-241. 2016.

OLIVEIRA, J. C. S. de. O.; VASCONCELOS, H. C. G.; PEREIRA, S. W. M.; NAHUM, V. J. I.; JUNIOR, A. P. T. Caracterização da pesca no Reservatório e áreas adjacentes da UHE Coaracy Nunes, Ferreira Gomes, Amapá Brasil. Biota Amazônia. v. 3, n.3, p.83-96. 2013.

PEREIRA, J. P. R.; SCHIAVETTI, A. Conhecimentos e usos da fauna cinegética pelos caçadores indígenas "Tupinambá de Olivença" (Bahia). Biota Neotropica. v. 10, n.1, p.176183. 2010.

RIBEIRO, A. S. S.; PALHA, M. das D. C.; TOURINHO, M. M.; WHITEMAN, C. W.; SILVA, A. do S. L. da. Utilização dos recursos naturais por comunidades humanas do Parque Ecoturístico do Guamá, Belém, Pará. Acta amazônica. v.37, n.2, p.235-240. 2007.

ROSAS, G. K. C.; DRUMOND, P. M. Caracterização da caça de subsistência em dois seringais localizados no Estado do Acre (Amazônia, Brasil). 1 Ed. Embrapa Acre. Rio Branco, AC. 2007. 31p.

SANTANA, A. C. de.; BENTES, E. dos. S.; HOMMA, A. K. O.; OLIVEIRA, F. de A.; OLIVEIRA, C. M. de. Influência da barragem de Tucuruí no desempenho da pesca artesanal, Estado do Pará. Revista de Economia e Sociologia Rural. v. 52, n. 2, p. 249-266. 2014.

SANTOS, G. M.; SANTOS, A. C. M. Sustentabilidade da pesca na Amazônia. Estudos Avançados. v.19, n. 54, p. 165-182. 2005.

SANTOS, G. M. dos.; OLIVEIRA JR, A. B. de. A pesca no reservatório da hidrelétrica de Balbina (Amazonas, Brasil). Acta Amazonica. v.29, n.1, p.145-163. 1999. 
SANTOS, G. M. dos. Impactos da Hidrelétrica Samuel sobre as comunidades de peixes do Rio Jamari (Rondônia, Brasil). Acta Amazonica. v. 25, n.3/4, p.247-280. 1995.

SILVA, M. A. da.; ARIDE, P. H. R.; SANTOS, S. M. dos.; ARAÚJO, R. L.; PANTOJA-LIMA, J.; BRAGA, T. M. P.; OLIVEIRA, A. T. de. Preferências e restrições alimentares de moradores do município de Juruá, Amazonas. Scientia Amazonia. v.3, n.1, p.106-111. 2014.

SILVA, J. T. da.; BRAGA, T. M. P. Etnoictiologia de pescadores artesanais da comunidade Surucuá (Reserva Extrativista Tapajós-Arapiuns). Amazônica Revista de Antropologia. v.9, n.1, p.238-257. 2017.

SILVA, J. T. da.; BRAGA, T. M. P. Caracterização da Pesca na comunidade de Surucuá (Resex Tapajós Arapiuns). Biota Amazônia. v.6, n.3, p.55-62. 2016.

SILVA, S. H.; NODA, S. N. A dinâmica entre as águas e terras na Amazônia e seus efeitos sobre as várzeas. Revista Ambiente e Água. v.11, n. 2, p.378-386. 2016.

SILVA, A. L. da. Entre tradições e modernidade: conhecimento ecológico local, conflitos de pesca e manejo pesqueiro no rio negro, Brasil. Boletim do Museu Emilio Goeldi. Ciências Humanas. v.6, n.1, p.141163. 2011.

SIOLI, H. Studies in Amazonian waters. Atas do Simpósio sobre a Biota Amazônica. v.3, p.9-50. 1967.

SCHORK, G.; HERMES-SILVA, S.; BEUX, L. F.; ZANIBONI-FILHO, E.; NUÑER, A. P. de O. Diagnóstico da pesca artesanal na Usina Hidrelétrica de Machadinho, Alto Rio Uruguai - Brasil. Boletim do Instituto de Pesca. v.38, n.2, p.97-108. 2012.

SOUZA, M. F.; MARQUES, E. E.; MIRANDA, E. B.; ARAUJO, A. F. Do Rio Tocantins a Hidrelétrica de Peixe Angical: os peixes e as pescarias na memória dos pescadores. Revista Interface. n.12, p.119134. 2016.
SMITH, N. J. H. Quelônios aquáticos da Amazônia: um recurso ameaçado. Acta Amazonica. v.9, n.1, p.87-97. 1979.

TERRA, A. K.; REBÊLO, G. H. O uso da fauna pelos moradores da Comunidade São João e Colônia Central. In: SANTOS-SILVA, E. N.; APRILE, F. M.; SCUDELLER, V. V.; MELO, S. Diversidade Biológica e Sociocultural do Baixo Rio Negro, Amazônia Central, Editora INPA, Manaus, 2005.

ZACARDI, D. M.; SARAIVA, M. L.; VAZ, E. de M. Caracterização da pesca artesanal praticada nos lagos Mapiri e Papucu às margens do Rio Tapajós, Santarém, Pará. Revista Brasileira de Engenharia de Pesca. v.10, n. 1, p. 31-43. 2017. 